\title{
Use of the Mayfield horseshoe headrest for management of burns of the neck
}

\author{
Chenicheri Balakrishnan MD, Thomas A Pane MD
}

C Balakrishnan, TA Pane. Use of the Mayfield horseshoe headrest for management of burns of the neck. Can J Plast Surg 2005;13(2):83-84.

Proper positioning of a patient facilitates access and decreases frustration during surgical debridement of circumferential burns of the neck. The Mayfield swivel horseshoe headrest (Integra, USA) provides cranial support in either the supine or prone position for excision and skin grafting of the circumferential burns of the neck. This headrest can also be used during reconstruction of the neck.

Key Words: Mayfield horseshoe headrest

\section{Utilisation de l'appui-tête de Mayfield en forme de fer à cheval pour le traitement des brûlures au cou}

Le positionnement adéquat d'un patient facilite l'accès aux lésions et réduit la frustration lors du débridement chirurgical des brûlures circonférentielles du cou. Un appui-tête pivotant de Mayfield en forme de fer à cheval (Integra, É.-U.) fournit le soutien crânien nécessaire en décubitus ventral ou dorsal pour l'excision et les greffes cutanées des brûlures circonférentielles du cou. Cet appui-tête peut aussi être utilisé durant la reconstruction du cou en chirurgie plastique.

Dositioning the patient for the excision of burn wounds of the neck has been challenging due to the inability to get around the neck. Access to the circumferential burns of the neck can be achieved using a Mayfield horseshoe headrest (Integra, USA), and we recommend its use.

\section{MATERIALS AND METHODS}

\section{Mayfield horseshoe headrest}

The Mayfield horseshoe headrest has an adjustable pad base, which accommodates various head sizes and has multipositioning capabilities. The pressure-sensitive gel pad reduces chances of pressure necrosis and is fluid-resistant. The swivel horseshoe headrest provides cranial support for adults and older children and enables the head and neck to be positioned using both vertical and lateral movements. It can be used in both supine and prone positions. The horseshoe headrest enables easy access to the circumference of the neck, and the open area accomodates the chin. The headrest is positioned at the end of a standard operating room table, and the swivel arm aids in adjusting the height of the horseshoe. The Mayfield horseshoe headrest is available in two sizes: the pediatric horseshoe headrest for premature infants and young children; and the swivel horseshoe headrest suitable for adults, teenagers and older children.

Over a four-year period, five patients with circumferential neck burns were positioned in the operating room, using the Mayfield swivel horseshoe headrest to allow access to the neck. All patients were cleared of cervical spine injuries at the time of

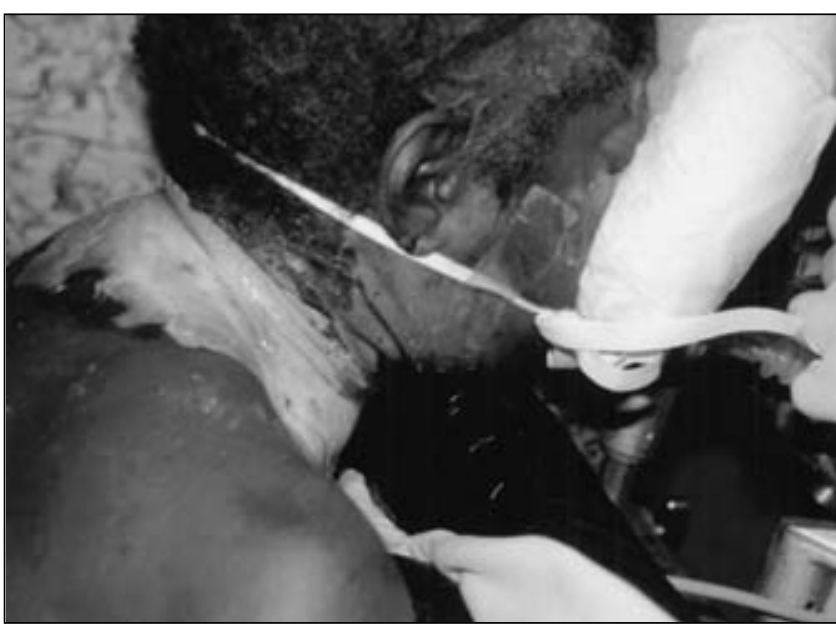

Figure 1) Patient in prone position with head supported by the Mayfield horseshoe headrest (Integra, USA)

admission. As demonstrated in Figure 1, placing the patient in the prone position allows the surgeon to readily access the posterior and lateral neck. Slight extension of the neck provides better access to the anterior neck.

The head is taped to the foam headrest after applying eye pads, and the torso of the patient is strapped to the operating room table 
to enable lateral tilt of the table as needed for positioning during tangential excision of the neck burns. Sterile drapes are used to cover the adjustable arm during the surgical procedure.

\section{DISCUSSION}

Various techniques have been used to aid in the surgical management of the burn patient $(1,2)$. Better positioning of the patient enables the surgeon to have adequate access and decreases the need for repositioning of the patient during the surgical procedures.

The Mayfield horseshoe headrest, which is commonly used by neurosurgeons for access to the neck and proper preoperative positioning of the patient, provides good access to the neck in a burn patient. The horseshoe supports the forehead and cheeks while avoiding any pressure over the eyes and chin. It provides stability and enables lateral tilting as needed during the procedure. The gel pad prevents pressure necrosis and is waterproof. The adjustable pad base accommodates various head sizes. There is access to the circumference of the neck both in the supine and prone position. The neck can be flexed or extended. The Mayfield headrest has also been used to achieve the prone positioning necessary to perform certain types of ophthalmological procedures such as unfolding of the inverted flap of a giant retinal break (3).

Due to its versatility, we recommend its use in positioning patients with circumferential burns of the neck and for reconstruction of the neck. The Mayfield horseshoe headrest can also be used to place the tissue expanders over the lateral neck.

\section{REFERENCES}

1. Davis JW, Hansbrough JF. Use of overhead hooks in burn surgery. J Burn Care Rehabil 1988;9:492.

2. Balakrishnan $\mathrm{C}$. The use of an orthopedic fracture table in burn surgery. Burns 1995;21:156.

3. Schwartz PL, Fastenberg DW, Wollman SB. The use of the Mayfield headrest to perform retinal surgery in the prone position. Ophthalmic Surg 1984;15:746-8. 